Article

\title{
Renewable Energy Options for a Rural Village in North Korea
}

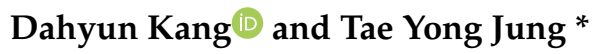 \\ Graduate School of International Studies, Yonsei University, Seoul 03722, Korea; dkang907@yonsei.ac.kr or \\ dianakang90700@gmail.com \\ * Correspondence: tyjung00@yonsei.ac.kr; Tel.: +82-2-2123-3594
}

Received: 3 February 2020; Accepted: 15 March 2020; Published: 20 March 2020

\begin{abstract}
The national electrification rate of North Korea is extremely low and the situation in rural areas is even worse. Thus, this study designs a virtual electrification project for a rural village in North Pyongan and compares an off-grid energy system and on-grid system in terms of net present cost (NPC) and levelized cost of energy (LCOE) to define the most cost-effective energy system. Using Hybrid Optimization of Multiple Energy Resources (HOMER), this study designs two off-grid systems that apply different types of batteries-lead-acid and lithium-ion energy storage systems (ESS) - and determines the NPC and LCOE of the most cost-effective system. Then, it calculates the NPC and LCOE of grid extension by adding necessary costs required for generation, transmission, and distribution. The result shows that the hybrid energy system (HES) of solar photovoltaic (PV), wind turbines, lead-acid batteries, and diesel generators is the most cost-effective option for the selected location. The range of breakeven grid-extension distance is from $9.69 \mathrm{~km}$ to $20.57 \mathrm{~km}$. The sensitivity analysis based on different discount rates shows that a higher discount rate means a shorter breakeven distance. This analysis suggests that deploying an HES is one way to improve the electrification rate for remote and rural areas in North Korea.
\end{abstract}

Keywords: rural electrification; hybrid energy system; renewable energy; lead-acid battery; ESS; grid extension; North Korea

\section{Introduction}

Energy is an important enabler for sustaining people's lives and achieving a country's economic development. Through technological advancement, the global energy access rate has been largely improved over the past few decades. However, today, approximately 1 billion people around the world still have no access to electricity, and 2.7 billion people, which is equivalent to half the population in developing countries, rely on traditional fuels for cooking and heating [1]. The situation for rural areas in developing countries is even worse, as they lack resources and infrastructure for access to modern energy. Many rural electrification projects have taken the approach of a grid-extension option, as it is considered a conventional way of supplying electricity. However, high reliance on the traditional fuels is not sustainable and exacerbates environmental damage. Therefore, the rural electrification project should aim for improving not just the energy access rate, but also access to sustainable energy services.

Many recent studies have confirmed that off-grid energy systems are economically viable, particularly in the areas with special geographical features, such as island or landlocked states. Lal and Raturi (2012) conducted a techno-economic analysis of a hybrid mini-grid system for the Fiji Islands and found out that the hybrid energy system (HES) of a PV, wind turbine, and diesel generator is the most ideal option [2]. In the study of a small island in Greece which suffers from electricity shortage, the system configuration of a PV, wind turbine, battery, and internal combustion electrical generator using biogas is proposed as an optimal energy system that can meet the electrical and thermal demands 
of the island [3]. Similarly, in the case of a resort located in Kuda Bandos Island in the Maldives, Jung et al. (2018) found out that a PV system incorporated with an energy storage system (ESS) is economically feasible and can reach grid-parity within the project lifetime, though a system with an advanced ESS remains an expensive option [4]. While these studies have used Hybrid Optimization of Multiple Energy Resources (HOMER) for techno-economic feasibility analyses, Nernini et al. (2014) took a different approach by using a multi-criteria analysis and presented a number of benefits of deploying renewable and HESs in isolated areas, like the Brazilian Amazon [5].

The economic viability of an off-grid energy system is also confirmed in many case studies of remote rural areas. The studies are particularly concentrated in African and South Asian countries, since most of these countries encounter the issues of not only energy shortage, but also adverse climate change impacts, and therefore need to find a way to supply energy in a more sustainable way. According to Mondal and Denich (2009), the study compared and analyzed the different configurations of renewable energy systems (RESs) for three remote rural areas in Bangladesh in order to define the optimal system as well as its optimum size [6]. The analysis results showed that the HES, including $6 \mathrm{~kW}$ of PV, a $10 \mathrm{~kW}$ diesel generator, and a battery is the most economically feasible option for the target location. A similar study was conducted in Shahzad et al. (2017) for a remote rural village in the Punjab province of Pakistan, which mainly consists of agricultural farms and residential houses [7]. This study performed HOMER simulation along with cost analysis and determined that the hybrid system of PV and biomass is economically feasible to be deployed in this region. The feasibility analysis of the HES of PV and a low-cost and advanced type of ESS was performed for a remote rural village in Myanmar by Kim and Jung (2018) [8]. This study suggested that, although the rural village in Myanmar lacks resources, a leap-frogging approach which indicates the adoption of an advanced type of ESS in the HES is an economically viable option. The economic feasibility of HES is also proven in case studies of Nigeria. Ani and Abubakar (2015) designed a hypothetical electrification project for a rural health clinic in Nigeria and showed that the HES of PV, wind turbine, and battery is suitable for the health clinic and can be employed in other places where the electrical demand is relatively low [9].

There are some studies which have taken a step further to determine the break-even grid-extension distance to observe to what extent the off-grid system is recommended. Using HOMER, Brenna et al. (2016) tested various system configurations for a rural community located far away from Addis Abba and computed the break-even grid-extension distance for each of the top three optimal systems [10]. The computed break-even distances are between 45.7 and $48.3 \mathrm{~km}$, depending on the system configuration. As the study location is $100 \mathrm{~km}$ away from the nearest grid, the off-grid system is suggested for the selected location. Yimen et al. (2018) also performed a techno-economic analysis of a renewable energy system (HRES) for a rural area in Cameroon and determined the break-even distance of $12.78 \mathrm{~km}$ [11]. Since the selected location is $18 \mathrm{~km}$ away from the power transformer, the study concluded that the proposed HRES is a better option.

Based on the aforementioned studies, the off-grid energy system is confirmed as an economically viable option in many islands and remote rural areas. However, there are few studies focused on the renewable energy system in North Korea due to the limited information and data of the country. Among the few studies on North Korea's energy system, a couple of reports have highlighted the potential for renewable energy development in North Korea. According to Kwak (2018), North Korea is currently active in developing a mini-grid system by enacting relevant laws and policies, and there is a rising number of houses and commercial buildings in North Korea that are being established with solar panels these days [12]. Thus, this study assessed that the potential for renewable energy systems, particularly solar PV systems, is high in North Korea. Bing and Lee (2017) pointed out the rich renewable resources in North Korea and viewed that the prospect of a renewable energy system is bright in North Korea [13].

Considering these points, this study designs a virtual electrification project for a small rural village in North Korea and compares the net present costs (NPCs) and levelized costs of energy (LCOEs) of off-grid systems and grid extension in order to determine the most cost-effective system. Moreover, 
this study computes the break-even grid-extension distance to confirm the cost-effectiveness of the off-grid system for the selected location. This study has its significance in two aspects. First, to the authors' best knowledge, this study is the first to perform the cost analysis of an off-grid system for North Korea using a quantitative method. Although Kwak (2018) and Bing and Lee (2017) evaluated the off-grid system in North Korea, the arguments made in both reports are qualitative assessments based upon the news articles and macroeconomic indicators of North Korea, which is different from our study. This study proves the cost-effectiveness of the off-grid system through the NPCs, LCOEs, and break-even distances computed using HOMER and cost calculations. Second, it is the first study focusing on a rural area of North Korea in the context of energy development. Like Kwak (2018) and Bing and Lee (2017), Kim and Kim (2019) provide an analysis of North Korea's energy sector, but this is a country-level evaluation which focuses on air pollutants caused by the energy sector [14]. Our study, however, provides a site-specific analysis focusing on a rural village in North Pyongan, North Korea by utilizing the meteorological data of the site, and explores the question of whether the off-grid system is more cost-effective than the grid extension.

This paper is structured as follows. In the Section 2, it provides an overview of the energy situation by providing the electrification rate, trend of energy supply, and generation by source in North Korea. Section 3 mainly discusses how this study is designed to compare the off-grid system and on-grid system. It also describes in detail the input data for a HOMER simulation. In addition, the cost data and equations used for estimating the NPC and LCOE of grid extension are also introduced in Section 1. Section 4 mainly discusses the results and analysis of our study. It first provides the comparison of the NPCs and LCOEs of on-grid and off-grid energy systems. Then, it describes how the break-even distance of an off-grid system is calculated, and presents the results. Then, a sensitivity analysis is carried out to ascertain how the results change depending on different discount rates. Lastly, Section 5 summarizes this study's findings with some implications.

\section{Overview of Energy Situation in North Korea}

The power sector of North Korea currently faces many challenges. The national electrification rate of North Korea is only 27 percent, which is far below the 89 percent average for developing Asian countries [15] (p. 116). The situation in rural areas is even worse, as only 11 percent of the rural population has access to electricity, whereas the average of developing Asian countries is 81 percent (see Figure 1). The Energy Information Administration (EIA) also indicates that many existing electricity infrastructures in North Korea are outdated and in need of repair [16]. North Korea's electrification rate, therefore, is currently ranked at the bottom for developing Asian countries.

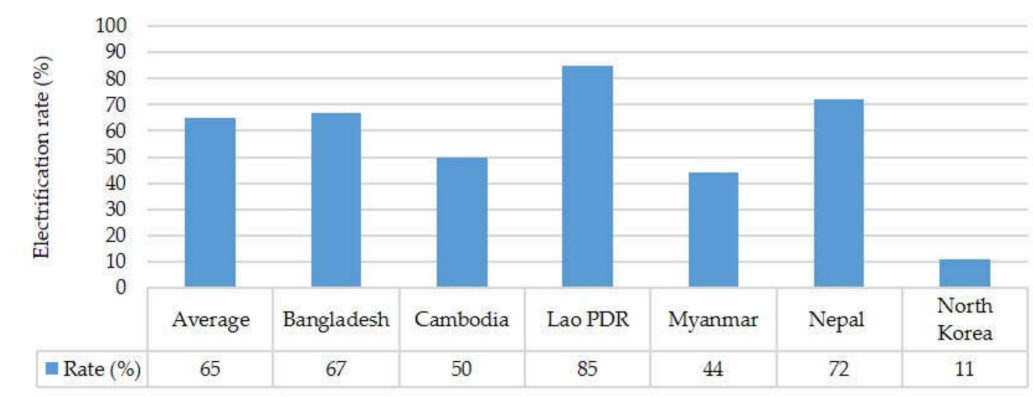

Figure 1. Rural electrification rate of developing Asian countries [15].

North Korea's electricity supply shows a decreasing trend. The supply has been significantly reduced over the past approximately three decades. Due to the Arduous March, one of the greatest famines and economic downturns in North Korean history, the energy supply as well as demand plummeted in the early 1990s, as shown in Figure 2. Since then, North Korea has experienced difficulty in recovering from the downturn. The total energy supply was only 9,910 Tonnes of Oil Equivalent (TOE) in 2016 [17]. This indicates that North Korea is suffering from a chronic electricity shortage. 


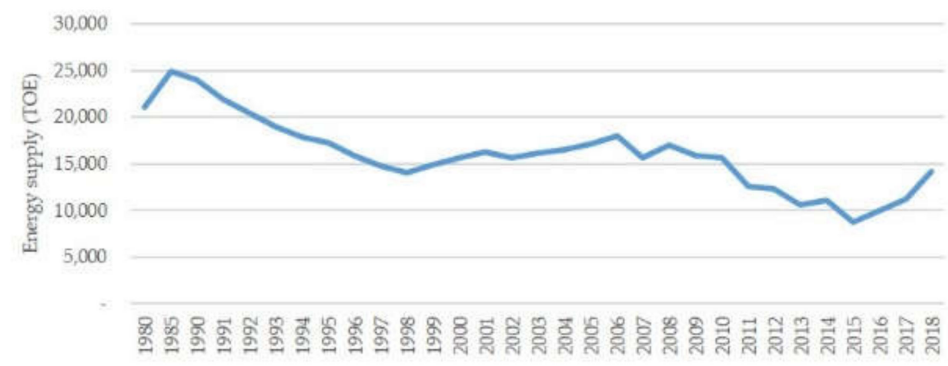

Figure 2. Trend of energy supply in North Korea [17].

Another serious problem intrinsic to the North Korean power sector is heavy reliance on traditional fuels, particularly coal and hydropower. As shown in Figure 3, coal and hydropower have long been the two main energy sources in North Korea. The heavy reliance on these sources is problematic for North Korea, since it leads to depletion of natural resources and environmental destruction. From 2000, North Korea began to construct dams in order to increase power generation, which, in fact, increased the proportion of hydropower generation (see Figure 3, [17]). However, the dams were constructed without a thorough review of their environmental impact, which resulted in serious environmental consequences, such as the collapse of the ecosystem and frequent landslides [18] (p. 26). In addition, North Korea has maximized the use of coal in power generation, as it is endowed with rich mineral reserves [19]. However, coal accounts for almost 50 percent of the power generation sources, which suggests that coal is over-extracted and supplies are likely to be depleted in the near future. Moreover, many North Koreans are currently using biomass as a daily energy source, mostly wood and crops [18] (pp. 25). This is also a burden for the environment, as it leads to excessive logging and causes deforestation. Considering these aspects, North Korea should seek a way to increase electricity generation in more environmentally sustainable ways.

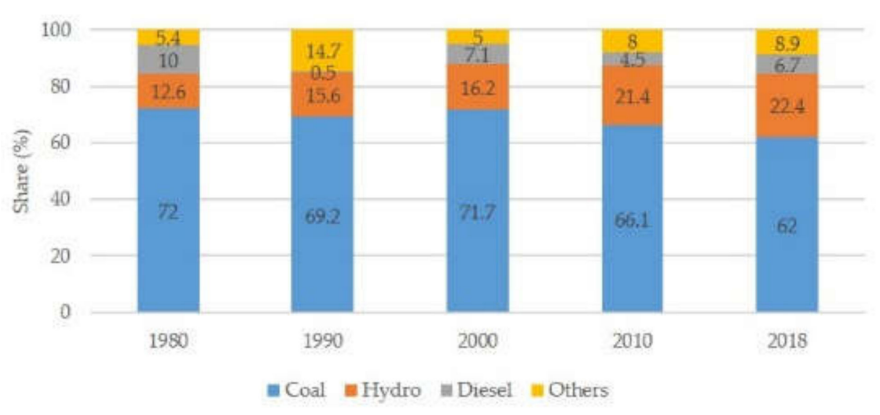

Figure 3. Energy supply by source in North Korea [17].

\section{Materials and Methods}

This study is designed for a small village located in Kibong-ri, Cholsan-gun, North Pyongan $(39.5975,124.6311)$, an un-electrified rural area [20-22] (pp. 35, see Figure 4). Based on Bing and Lee (2017), the area along the west coast in North Korea has rich wind resources, particularly in the summer, so it is known as an ideal environment for wind power generation [13] (pp. 47, 49-51). In addition, the average daily radiation of the site is higher than in the northern European countries, namely France and Germany [13] (pp.56). These facts indicate that the site has favorable conditions for an off-grid system. In Section 3, the NPCs and the LCOEs of off-grid and on-grid systems are compared to find the most cost-effective energy system for the selected location. HOMER is used as a simulation tool for testing the economic and technical viability of different energy system configurations, which include solar PV, wind turbines, diesel generators, and batteries. In this process, two types of energy system configurations are tested based upon battery type: A conventional type of lead-acid battery and an advanced type of lithium-ion based ESS. After comparing the NPCs and LCOEs of an off-grid system 
and grid extension, this study also finds the range of break-even grid-extension distances. In the end, this study observes how this range changes in relation to different discount rates.

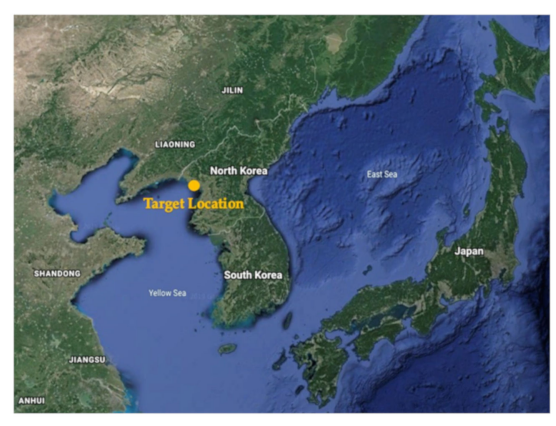

(a)

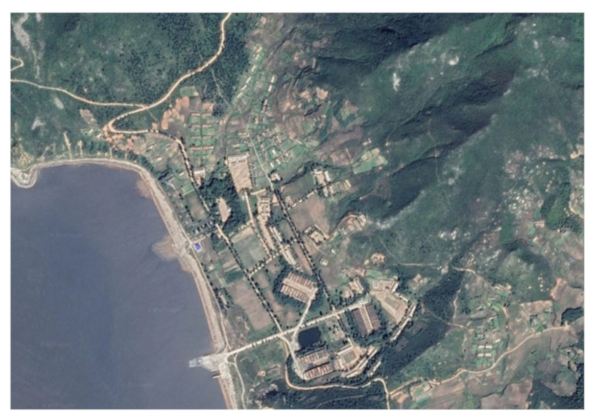

(b)

Figure 4. (a) Map of North Korea [21]; (b) map of the selected site in Kibong-ri, Cholsan-gun, North Pyongan [22].

\subsection{HOMER Simulation for an Off-Grid System}

The HOMER simulation software, developed by the National Renewable Energy Laboratory (NREL) in the United States, allows the user to design various types of energy systems by inputting the technical specifications and costs of system components. The system components as well as natural resources can be defined by either HOMER or the user. HOMER contains a library of system components, of which it contains the data and technical specifications. In addition, it also includes up-to-date data on natural resources, such as solar radiation, temperature, and wind speed. However, the data of these components can be customized by the user. Lastly, the user should input the hourly electrical load of the selected site. With these data inputs, HOMER performs numerous simulations to define an optimal system that matches the supply and demand to serve desired loads. In addition, it allows the user to conduct sensitivity analyses for further assessment. Due to the various functions of HOMER with customized options, many studies have used it as a tool for conducting techno-economic feasibility analyses of off-grid energy systems [3,6-8,11,23-25]. Due to the various functions within HOMER with customized options, this study also uses HOMER to derive the NPC and LCOE of the most effective off-grid energy system for the selected location.

\subsubsection{Load}

The energy load is one of the important input factors in HOMER simulation. HOMER requires an hourly energy load in order to test the technical feasibility of a system designed in HOMER, or whether the system could meet different loads by hour. However, the target location is currently unelectrified, and it is nearly impossible to obtain the data for the actual energy loads of rural residential areas in North Korea at this moment. Thus, this study uses a synthesized load based on survey results about residential energy consumption gathered from 257 North Korean defectors [18] (pp. 37). This survey asked in detail about the defectors' hometowns and the types and daily usages of electrical appliances used at their houses in North Korea. We apply this information to configuring home appliances and their usage when calculating the electric load. However, the results from the defectors from Pyongyang are excluded, as Pyongyang is one of the most developed cities in North Korea. This study also refers to several other studies on rural electrification to adjust the load and generate a more realistic load pattern for the selected village. In addition, this study assumes that each household in the village has four family members, as this is the most common size in the rural area of North Pyongan [26] (pp. 233-234).

Based on the survey results, we designed a household energy load, in which the energy is mainly used for lighting, entertaining, and cooling. This energy use pattern aligns with the energy demand for rural households in other regions [27]. In addition, this study includes energy demand for heating, 
since North Korea experiences cold winters, and there is evidence that some households use a small heater [18] (p. 23). Considering all of these, the electric load for a single household is calculated (see Table 1). There is variation in lighting usage, as households use 0.5 hours less and more during summer and winter, respectively, due to the timing of sunset and sunrise. In addition, fans and heaters are used only for summer and winter, respectively. We assume that there are 120 households in the village and calculate the total load.

Table 1. Calculation of the electric loads For households.

\begin{tabular}{cccccc}
\hline \multirow{2}{*}{ Item } & \multirow{2}{*}{ Energy $(\mathbf{W})$} & Unit & \multicolumn{3}{c}{ Use (h/d) } \\
\cline { 4 - 6 } & & & Spring, Fall & Summer & Winter \\
\hline Incandescent light & 50 & 2 & 5 & 4.5 & 5.5 \\
Compact fluorescent light & 150 & 2 & 2 & 1.5 & 2.5 \\
TV & 100 & 1 & 7 & 7 & 7 \\
Iron & 300 & 1 & 0.5 & 0.5 & 0.5 \\
Video Player & 40 & 1 & 2 & 2 & 2 \\
Charging & 20 & 1 & 4 & 4 & 4 \\
Washing machine & 240 & 1 & 1 & 1 & 1 \\
Stereo & 100 & 1 & 2 & 2 & 2 \\
Refrigerator & 80 & 1 & 24 & 24 & 24 \\
Fan & 30 & 1 & & 5 & 5 \\
Space heater & 200 & 1 & & & 4.01 \\
\hline
\end{tabular}

The load profile for this village in Kibong-ri shows variation throughout the day and the year. Based on the assumption and calculation, the electricity demand for this village is $5857 \mathrm{kWh}$ per year. The demand is low during spring and fall and high during winter due to the use of heaters (see Figure 5). The peak demand appears at nighttime, and a slight increase in demand in the morning and daytime from 11 to 12 (see Figure 6). We assume that the energy demand for a household reaches a peak when all family members are at home. Thus, we set the nighttime as the peak load time, when all family members return home from work or school. The hourly load patterns described in Figure 7. are typical for rural villages, as other rural residential areas show similar load patterns [28-31]. The demand at night is maximized in winter, as households use heaters at night. The demand increases in the morning, when people prepare to go to work and school, but this is not as high as the peak at night. There is a slight increase during the daytime for doing house chores, such as doing laundry and ironing. It is increased more during the summer, as households use fans during the daytime.

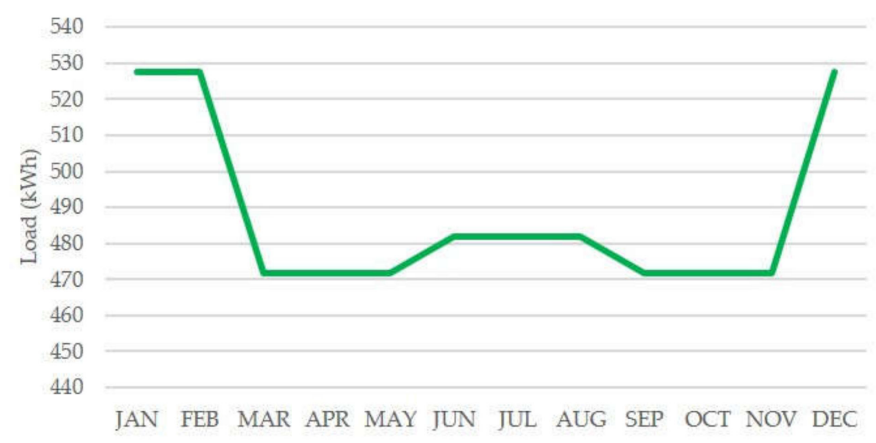

Figure 5. Monthly load for the village. 


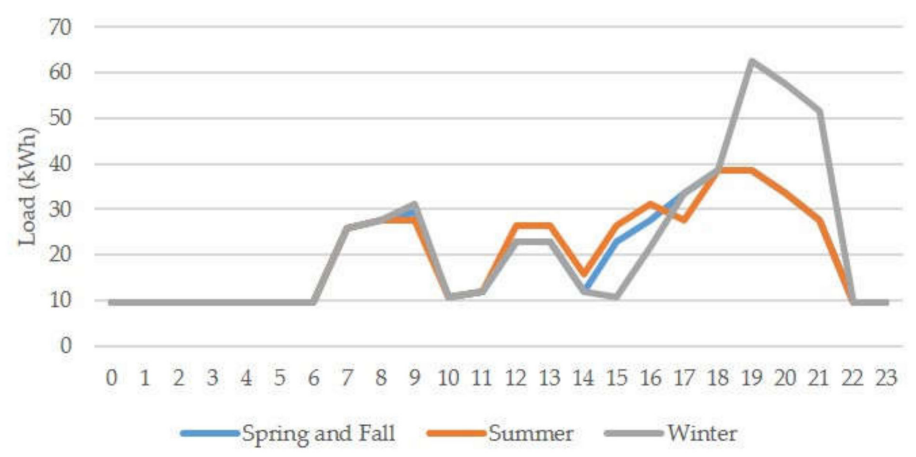

Figure 6. Hourly load for the village.

\subsubsection{System Inputs}

This study designs two types of energy system configurations based on different battery chemistries. In this study, a $1 \mathrm{~kW}$ of solar PV, a $100 \mathrm{~kW}$ wind turbine, and diesel generator are selected as base components for both system configurations, and one unit of either a lead-acid battery or lithium-ion battery is installed in each system configuration, as described in Figure 7. Since this is a rural electrification project in a developing country, we take the lowest-cost option by using low-cost PV and a wind turbine manufactured in China for the simulation. As described in Figure 7, this study applies a lead-acid battery and lithium-ion battery to each configuration in order to investigate the difference between NPC and LCOE due to the difference in battery chemistry and performance. Cost information is summarized in Table 2, and a detailed technical specification of each of the system components is listed in Appendix A.

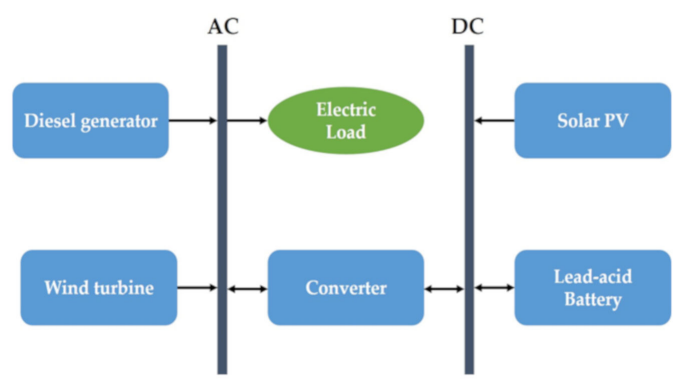

(a)

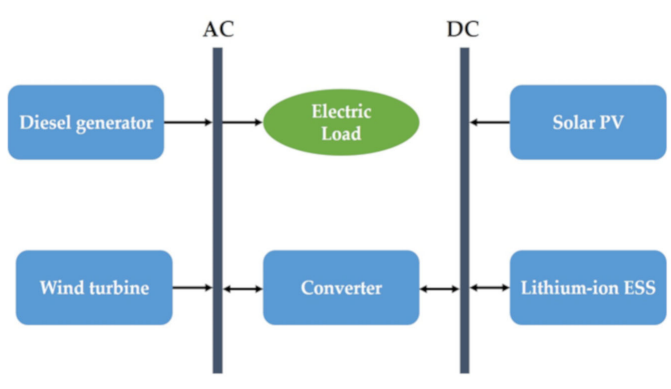

(b)

Figure 7. System configurations: (a) The energy system configuration using a lead-acid battery; (b) the energy system configuration using a lithium-ion battery.

Table 2. Summary of costs for an off-grid system.

\begin{tabular}{cccc}
\hline Component & Capital cost(\$/kW or \$/unit) & Annual O\&M (\$) & Replacement $\mathbf{( \$ / k W ) ~}$ \\
\hline PV & 1720 & 8.68 & 1720 \\
Wind turbine & $156,428.00$ & 2,647 & $156,428.00$ \\
Lead-acid battery & 1259 & 0.02 & 1100 \\
Lithium-ion ESS & 4500 & 90 & 4500 \\
Diesel generator & 500 & $0.003 /$ op.hr & 500 \\
Converter & 800 & 0 & 750 \\
\hline
\end{tabular}




\subsubsection{Renewable Resources}

The target location for this study is located at Kibong-ri, Cholsan-gun, North Pyongan, which is in the northwest of the country. As this site is adjacent to the Yellow Sea, it features an oceanic climate. The temperature is moderate throughout the year, and the annual average is estimated as $9.14^{\circ} \mathrm{C}[32,33]$. Such characteristics are favorable for operating PV systems because the systems do not operate at full capacity under extreme weather conditions.

The data on the solar global horizontal index (GHI) with the clearness index and wind speed for the selected site $(39.5975,124.6311)$ were retrieved from NASA and manually input in HOMER [33]. The annual average of daily radiation is $4.18 \mathrm{kWh} / \mathrm{m}^{2}$, with monthly variations; the highest and lowest radiation occurs in May and December, respectively (see Figure 8). From April to June, this site reaches higher levels of daily radiation, above $5.0 \mathrm{kWh} / \mathrm{m}^{2}$, whereas the radiation remains as low as $3.0 \mathrm{kWh} / \mathrm{m}^{2}$ from November to January. Another important factor determining the performance of the PV system is the clearness index, which is the fraction of radiation that reaches a location. Like the solar GHI, the clearness index of this site has monthly variations, but remains higher than 0.5 on most days, except during the rainy season, from June to August. Due to the geographical features, there is a strong wind coming from the Yellow Sea. The wind speed data was measured at $50 \mathrm{~m}$ above the ground, and the annual average of wind speed is $5.61 \mathrm{~m} / \mathrm{s}$ with slight variations by season (see Figure 9). The wind speed drops as low as $4.53 \mathrm{~m} / \mathrm{s}$ during the summer, but it remains higher than $5.0 \mathrm{~m} / \mathrm{s}$ on most days throughout the year.

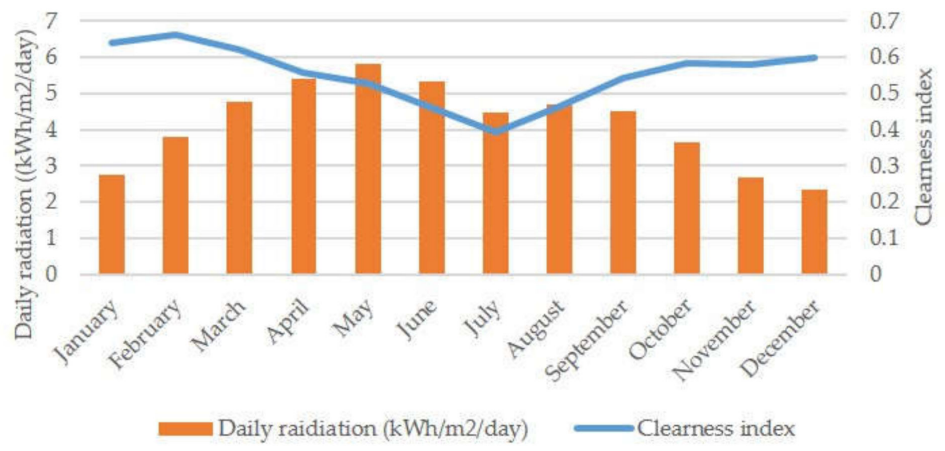

Figure 8. Annual solar global horizontal index (GHI) and clearness index [33].

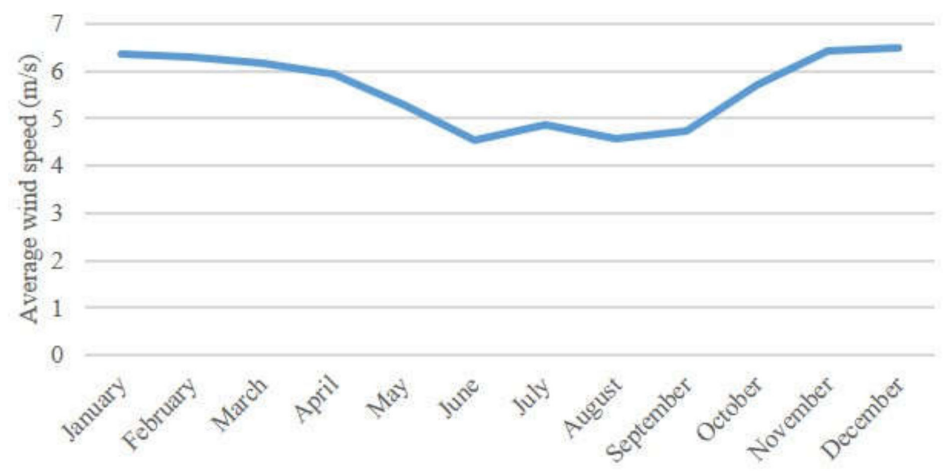

Figure 9. Annual wind speed [33].

\subsection{Calculation of NPC and LCOE for the On-Grid System}

The costs for a grid-extension system are largely divided into three components-generation, transmission, and distribution. Each of the three components is comprised of three sub-componentscapital cost, operation and maintenance $(\mathrm{O} \& \mathrm{M})$ cost, and replacement cost. There exist two power plants-hydro and coal—near the target village, and the study assumes the use of these two power 
plants. According to the Korea Development Bank (2014), the hydro and coal power plants located in Sinuiju and Anju are 70 and 40 years old, respectively [19] (pp. 148, 178). This indicates that the value of these facilities is nearly zero. For these reasons, we do not take into account the capital cost of generation in the calculation of NPC and LCOE. In addition, no major replacement is assumed for this study because the project is only focused on a 20 year long window. In general, there is a wide range of capital costs for transmission line construction. Thus, this study refers to three different sets of capital cost data and calculates a total of six NPCs and LCOEs.

\subsubsection{Generation Cost}

In this part, the annual O\&M cost and fuel cost are considered for calculating the generation cost. The fuel cost is only calculated in the case of coal generation. With the given values of heat rate and heat content, this study uses the equation described below (Equation (1)) and calculates the amount of coal required for generating $1 \mathrm{kWh}$ of power [34]. Using this calculated value and the energy load of the village with the price of coal set at $0.05 \mathrm{USD} / \mathrm{kg}$, the annual fuel cost for the coal power plant is calculated based on the equation presented below (Equation (2)). Referring to Dapice (2017) and Penn State College of Earth and Mineral Sciences, the annual O\&M costs for both cases of power generation are estimated $[35,36]$.

$$
\text { Amount of fuel used per } k W h=\frac{\text { Heat rate }(\text { Btu } / k W h)}{\text { Fuel heat content }(\text { Btu/short ton })}
$$

$$
\text { Annual Fuel Cost }=\text { Amount of fuel used per } k W h * \text { Coal price } * \text { Energy Load }
$$

\subsubsection{Transmission Cost}

Two cost components are considered for calculating the transmission cost: Capital cost and annual O\&M cost. The capital cost of transmission varies based on geographical features of the location and local labor costs. As this study focuses on a rural electrification project, it references costs from studies on rural electrification projects in South Africa, South Korea, and Myanmar with the range of costs between 18,232 to 43,500 USD/km $[8,37,38]$. Taking these costs into account, we have measured the distance between the power plants and the village to estimate the distance of transmission lines that need to be extended. The nearest coal-fired power plant is located in Anju, which is about $100 \mathrm{~km}$ away from the target village. The hydropower plant is located at the Chongchon River, and the nearest substation connected from this power plant is at Sinuiju, which is about $52 \mathrm{~km}$ away from the site $[18,19]$.

\subsubsection{Distribution Cost}

Similarly to transmission, the distribution process also comprises two types of cost components: capital cost of distribution lines and annual O\&M cost. Cost information from the Latin America case is used as a reference for calculating the capital cost. NRECA International, Ltd. (2010) presents five different single-phase lines along with the respective costs, which are presented as US dollar per kilometer [39]. In this study, the average of these five costs is used for calculating the capital cost. In addition, we estimate the distribution lines required for the village using Google Earth. In Figure 10, yellow-highlighted lines along the village roads represent the required distribution lines, which are estimated as $5.5 \mathrm{~km}$. Based on the Earth Institute (2014), the annual O\&M cost is assumed as 1 percent of the capital cost for distribution lines [40]. 


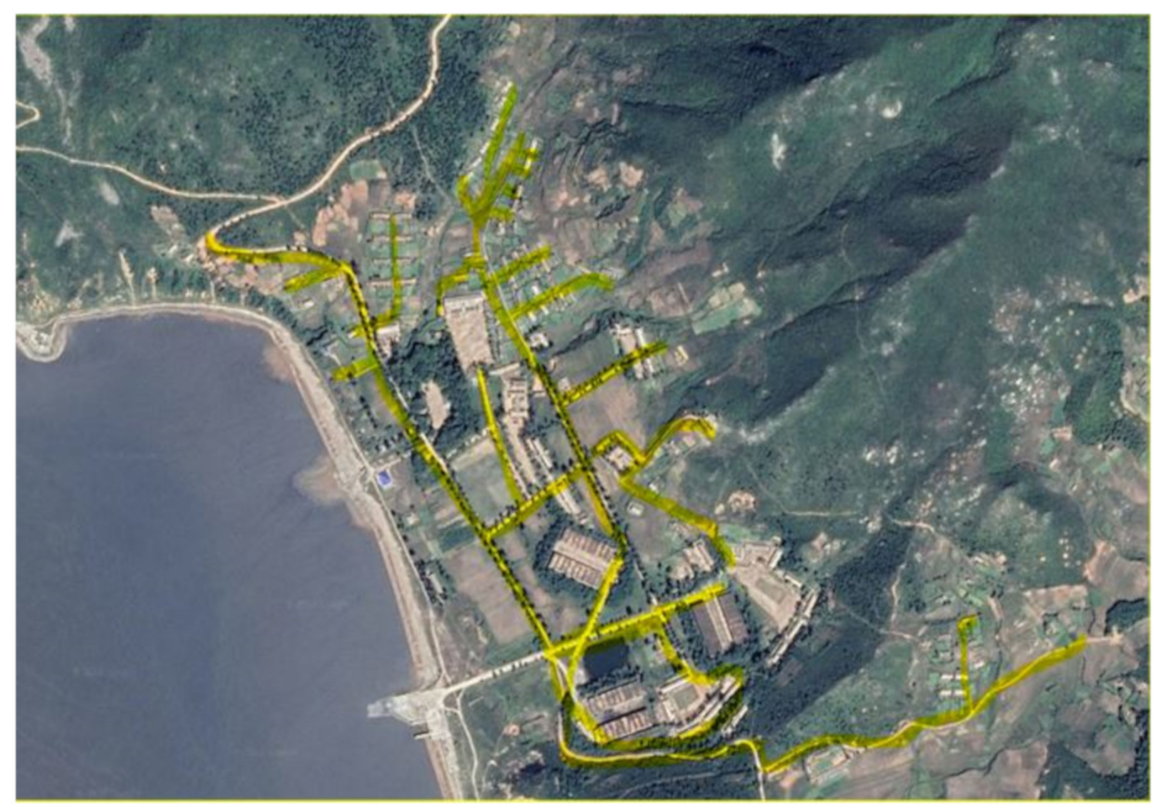

Figure 10. Distribution line of the village in Kibong-ri [22].

\section{Results and Discussion}

\subsection{Comparison of NPC and LCOE}

HOMER simulates all possible energy system configurations under given conditions and calculates the NPC and LCOE of each possible configuration. As we designed two types of off-grid energy systems depending on the type of battery, two simulation results were produced. Both Tables 3 and 4 present the simulation results of the energy system configurations using a lead-acid battery and ESS, respectively. Among all possible cases of energy system combinations, the lowest NPC and LCOE from an HES using a lead-acid battery were 472,719 USD and 0.25 USD, respectively, which are drawn from the case of using four system components. The result of an HES using a lithium-ion-based ESS was the same in that the combination of four system components yields the lowest NPC and LCOE, 514,814 USD and 0.27 USD, respectively. These results indicate that the combination of PV, wind turbine, diesel generator, and Battery Energy Storage System (BESS) is the most cost-effective energy system configuration for the selected location, regardless of battery chemistry.

Table 3. Hybrid Optimization of Multiple Energy Resources (HOMER) simulation results of an off-grid system using a lead-acid battery.

\begin{tabular}{|c|c|c|c|c|c|c|c|}
\hline Case & PV (kW) & Wind & $\begin{array}{c}\text { Diesel Generator } \\
(\mathrm{kW})\end{array}$ & $\begin{array}{c}\text { Battery } \\
(\mathrm{kW})\end{array}$ & $\begin{array}{c}\text { Converter } \\
(\mathrm{kW})\end{array}$ & NPC (\$) & LCOE (\$) \\
\hline 1 & 20.74297 & 1 & 110 & 27 & 39.371862 & 472,719 & 0.246593 \\
\hline 2 & & 2 & & 41 & 58.64107 & 493,366 & 0.257364 \\
\hline 3 & & 1 & 110 & 22 & 35.83858 & 495,108 & 0.258272 \\
\hline 4 & & 2 & 110 & & & 735,786 & 0.383821 \\
\hline 5 & 0.499172 & 2 & 110 & & 0.196346 & 736,023 & 0.383944 \\
\hline 6 & 92.14933 & & 110 & 94 & 44.03954 & 755,405 & 0.394055 \\
\hline 7 & 0.758313 & 4 & & 16 & 31.29019 & 797,141 & 0.415826 \\
\hline 8 & & & 110 & 57 & 23.28125 & $1,039,391$ & 0.542195 \\
\hline 9 & 308.5678 & & & 272 & 140.5141 & $1,115,580$ & 0.582338 \\
\hline 10 & 35.83317 & & 110 & & 19.401047 & $1,207,434$ & 0.629854 \\
\hline 11 & & & 110 & & & $1,239,456$ & 0.646559 \\
\hline 12 & & 8 & & & & $1,479,367$ & 0.771707 \\
\hline 13 & 2.020764 & 8 & & & 0.947586 & $1,483,741$ & 0.773989 \\
\hline
\end{tabular}


Table 4. HOMER simulation results of an off-grid system using a lithium-ion energy storage system (ESS).

\begin{tabular}{|c|c|c|c|c|c|c|c|}
\hline Case & PV (kW) & Wind & $\begin{array}{c}\text { Diesel Generator } \\
(\mathrm{kW})\end{array}$ & $\begin{array}{c}\text { Battery } \\
\text { (kW) }\end{array}$ & $\begin{array}{c}\text { Converter } \\
(\mathrm{kW})\end{array}$ & NPC (\$) & LCOE (\$) \\
\hline 1 & 15.08945 & 1 & 110 & 18 & 42.92099 & 514,814 & 0.268551 \\
\hline 2 & & 2 & 110 & 7 & 31.24798 & 521,644 & 0.272114 \\
\hline 3 & & 2 & & 21 & 65.70191 & 546,806 & 0.285304 \\
\hline 4 & & 2 & 110 & & & 735,786 & 0.383821 \\
\hline 5 & 0.549055 & 2 & 110 & & 0.333622 & 736,213 & 0.384043 \\
\hline 6 & 59.19638 & & 110 & 13 & 53.78017 & 758,353 & 0.395592 \\
\hline 7 & 0.504803 & 4 & & 7 & 31.81771 & 808,917 & 0.421969 \\
\hline 8 & & & 110 & 13 & 58.97917 & 899,512 & 0.469228 \\
\hline 9 & 35.83317 & & 110 & & 19.40104 & $1,207,434$ & 0.629854 \\
\hline 10 & & & 110 & & & $1,239,456$ & 0.646559 \\
\hline 11 & & 8 & & & & $1,479,367$ & 0.771707 \\
\hline 12 & 2.020764 & 8 & & & 0.947586 & $1,483,741$ & 0.773989 \\
\hline 13 & 423.4634 & & & 126 & 91.4259 & $1,504,320$ & 0.784975 \\
\hline
\end{tabular}

Figure 11 compares the NPCs of the most cost-effective cases derived from HOMER simulation to those of on-grid energy systems, and presents the share of generation, transmission, and distribution costs in each NPC. Since HOMER simulation provides the NPC, which takes into account only the energy generation factor, we add distribution costs on top of the NPCs generated by HOMER. In Figure 11, Systems 1 through 4 represent an on-grid system using coal generation, an on-grid system using hydro generation, an off-grid system using a lithium-ion ESS, and an off-grid system with a lead-acid battery, respectively. Cases 1, 2, and 3 represent the transmission costs from three different References $[8,37,38]$. Regardless of the power generation sources and types of transmission cost references, grid extension is more expensive than two off-grid energy systems. The high NPCs of System 1 and System 2 are the results of high transmission costs. Since the coal power plant is located further away from the selected site than the hydropower plant, the NPCs of System 1 are generally higher than those of System 2. System 3 and System 4 are, however, different in terms of the share of cost components that the power generation cost takes up, representing a majority portion in total NPCs. This is due to the fact that renewable energy systems require higher capital investment. Although the off-grid systems require a high generation cost, the transmission cost, a huge cost burden for on-grid systems, is absent in off-grid systems, which eventually makes the total NPCs of off-grid systems lower. Comparing Systems 3 and 4, the NPC of System 4 is slightly lower than that of System 3 , as the lead-acid battery equipped in System 4 is a conventional and low-price type of battery.

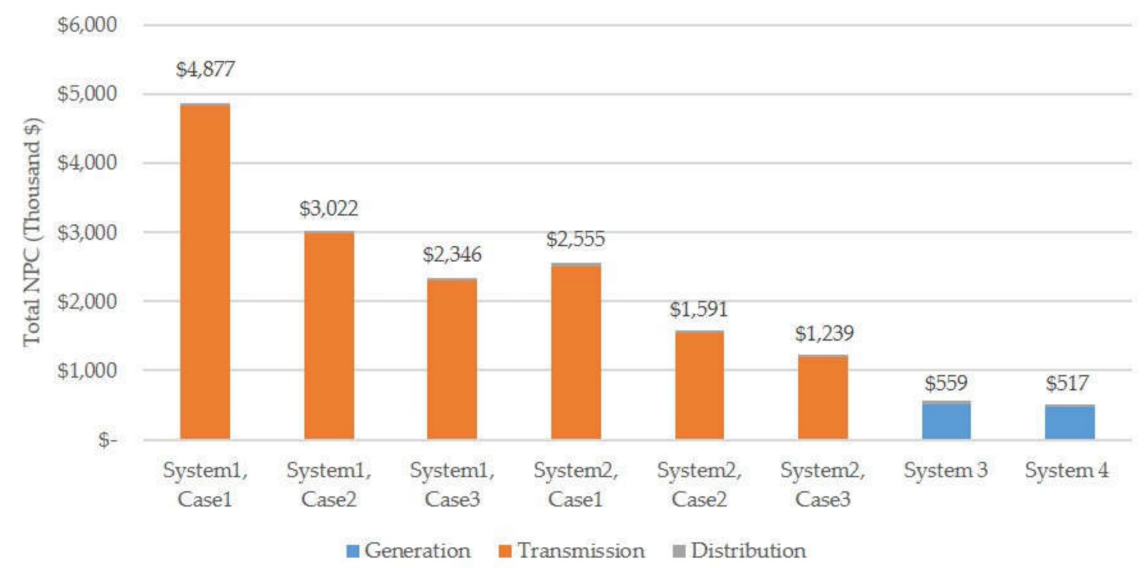

Figure 11. Comparison of net present cost (NPC).

Based on the results of the calculated NPCs, we compare the LCOE of each system and case to determine the most cost-effective energy system for the target village. In Figure 12, because of the 
higher NPCs in Systems 1 and 2, the LCOEs of these two systems are much higher than those of the other two systems. Depending on the case of the transmission capital cost, the LCOEs of System 1 vary from 1.74 to 3.55 USD, and those of System 2 vary from 0.86 to 1.81 USD. The LCOEs of Systems 3 and 4, however, are much lower. Even the option of applying the lithium-ion-based ESS yields an LCOE of 0.27 USD, which is lower than all cases of on-grid systems. The most cost-effective option is System 4, with a lead-acid battery, whose LCOE is estimated as the lowest at 0.25 USD. However, there is no significant gap in LCOE between Systems 3 and 4. Overall, the LCOE comparison shows that deploying an HES combining PV, wind turbines, diesel generators, and BESS is preferred over the grid-extension option in the case of the rural village in Kibong-ri, and the most cost-effective system is determined to be the HES with a lead-acid battery.

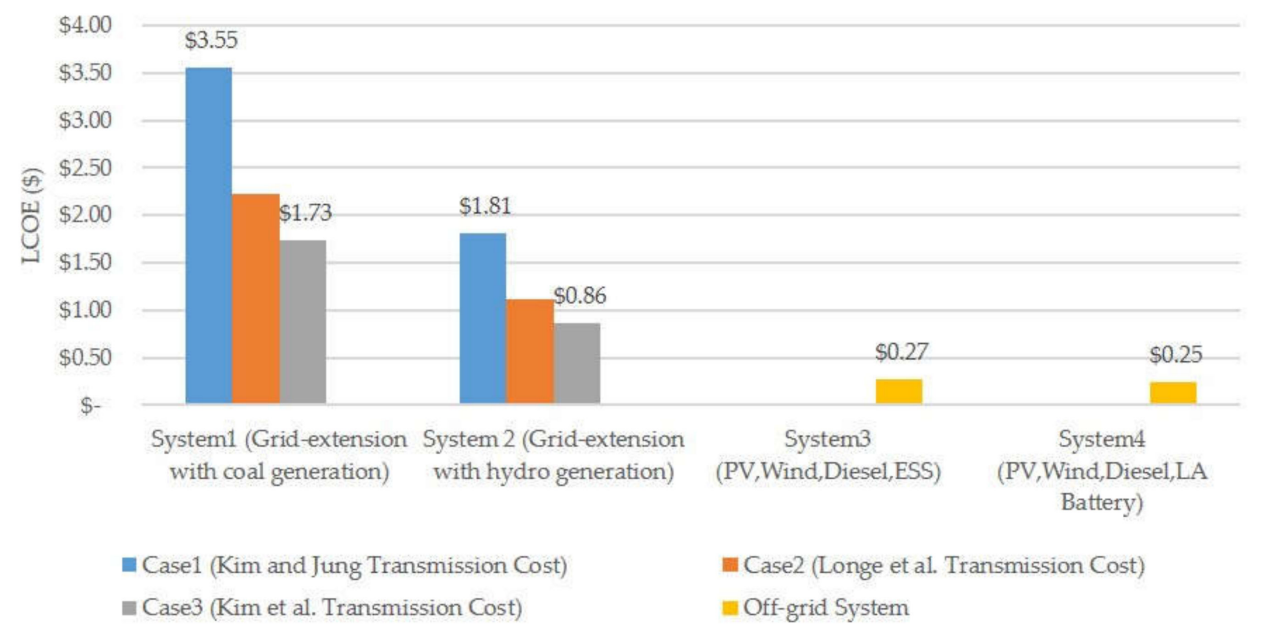

Figure 12. Comparison of levelized costs of energy (LCOEs).

\subsection{Break-Even Distance}

The purpose of Section 4.2 is to identify break-even distance, which, in other words, indicates the maximum distance of transmission at which the on-grid system remains cost-effective. With respect to the six calculated NPCs of the on-grid system, six different break-even distances are calculated and presented in range.

Table 5 represents the cost components of both on-grid and off-grid systems with symbols. As presented, both systems have different values for each cost component. Transmission cost only applies to an on-grid system, and $\alpha$ is the key to finding the break-even distance in this study. The study sets the total costs of both systems, excluding the common component of the distribution cost, as equal (Equation (3)). By the definition of the break-even distance, it indicates the tipping point at which the total costs of both systems are the same, so that it is the first step for determining the break-even distance. Using Equation (3) and the generation costs of both systems, the transmission cost, $\alpha$, which makes the total costs of both systems equal, is calculated. The computed $\alpha$ is then set as equal to the sum of the transmission cost over the lifetime (Equation (4)). The right-hand side of Equation (4) was previously used for calculating the NPC of transmission, where I indicates the initial investment cost, $M$ indicates the annual O\&M cost of transmission systems, and $r$ indicates the discount rate. In the calculation of transmission cost, a dollar-per-kilometer cost is used, and $x$ refers to the transmission distance. In Equation (4), $x$ essentially indicates the break-even distance and is calculated based on the given data. The calculation results are presented in Figure 13. If we assume that we deploy System 3, which is defined as the second most cost-effective option, the range of the calculated break-even distance is between 10.57 and $22.40 \mathrm{~km}$ depending on the type of generation and the case of the transmission cost. The break-even distances become even shorter in the case of deploying the most cost-effective option, System 4, since it yields a lower NPC. The range of the calculated break-even 
distances is between 9.69 and $20.57 \mathrm{~km}$. In this case, the off-grid system will certainly remain the more cost-effective option if the required transmission line exceeds $9.69 \mathrm{~km}$. In other words, if a village is located more than $9.69 \mathrm{~km}$ away from the generation site or substation, deploying an off-grid system is more cost-effective. If we take the lowest cost assumption of an on-grid system, the breakeven distance does not exceed $21 \mathrm{~km}$. Since our target location requires at least $56 \mathrm{~km}$ of transmission line, this result justifies our finding that deploying a hybrid off-grid system is preferred for the selected site.

$$
\begin{gathered}
\alpha+\beta=\gamma \\
\alpha=\sum_{t=0}^{20} \frac{x\left(I_{t}+M_{t}\right)}{(1+r)^{t}}
\end{gathered}
$$

\begin{tabular}{|c|c|c|}
\hline Cost Components & On-Grid System & Off-Grid System \\
\hline Generation & $\beta$ & $\gamma$ \\
\hline Transmission & $\alpha$ & 0 \\
\hline Distribution & & \\
\hline Total Cost & $\alpha+\beta+\delta$ & $\gamma+\delta$ \\
\hline
\end{tabular}

Table 5. Cost components of on-grid and off-grid systems.

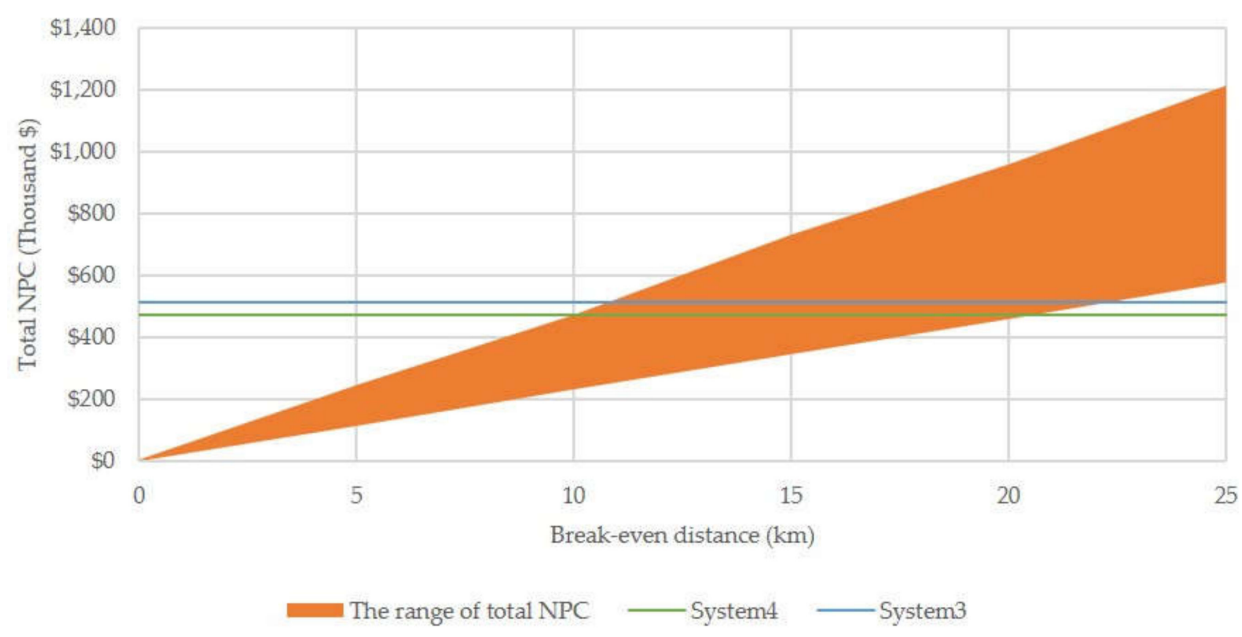

Figure 13. Break-even grid-extension distance.

\subsection{Sensitivity Analysis}

In this part, this study reflects changes in discount rates on our findings to observe how the results are affected by different discount rates. In the HOMER simulation and calculation of the on-grid system, this study applies a discount rate of 10 percent. To observe the changes in the NPCs and breakeven distances along with the different discount rates, we apply discount rates of 8 and 12 percent for sensitivity analysis.

The effect of the discount rate on the NPC as well as the break-even distance is presented in Figure 14. Two dots on each line represent the highest and lowest values of each discount rate. This shows that both the NPC and break-even distance decrease as discount rates increase from $8 \%$ to $12 \%$. If we assume that we deploy System 3, which is equipped with a lithium-ion ESS, the range of break-even distance is 10.10 and $21.70 \mathrm{~km}$ at the discount rate of $12 \%$. However, these distances become slightly longer as the discount rate decreases to $8 \%$, extending the range to between 10.80 and $22.64 \mathrm{~km}$. Assuming the deployment of System 4, which was proven as the most cost-effective system, using the lead-acid battery, the break-even distances become shorter. The shortest break-even distance at a discount rate of $12 \%$ is 9.35 , and the longest is $21.13 \mathrm{~km}$ at a discount rate of $8 \%$. Although the 
sensitivity results show a slight difference in the break-even distances, these results indicate that the off-grid system will be a more cost-effective option in the case of a high discount rate, as it shows a shorter break-even distance.

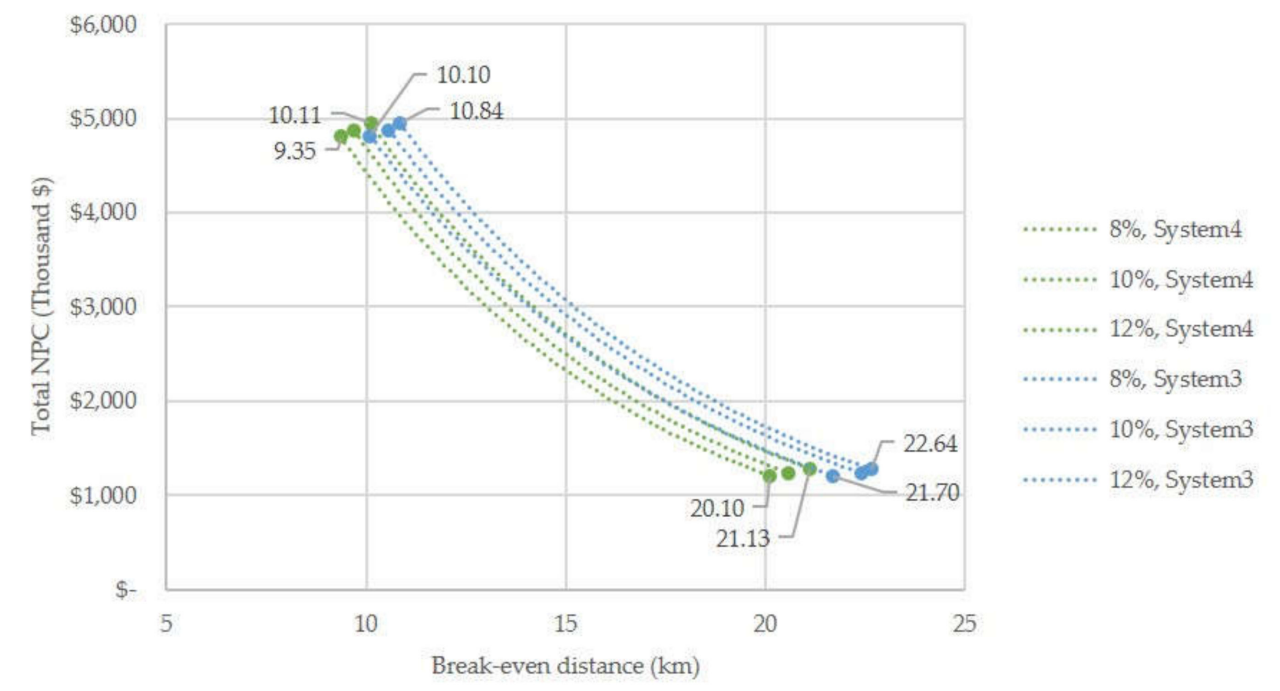

Figure 14. Sensitivity analysis on discount rates.

\section{Conclusions}

North Korea currently faces two critical issues in the energy sector. First, the national electrification rate is extremely low and the rate for rural areas is even lower. Another issue is the heavy reliance on traditional energy sources, which consistently exacerbates the environmental situation. Thus, the country needs to increase the energy supply by using more clean and renewable resources. In this case, the deployment of an off-grid system can be an optimal solution for the remote rural areas, as previously verified in many case studies. This study, therefore, has designed a virtual electrification project in a small rural village in North Pyongan, located far away from the grid, and investigated the most cost-effective option for the site. The cost comparison results showed that an HES equipped with a PV, wind turbine, battery, and diesel generator is found out to be the most cost-effective. Even an HES with a lithium-ion based ESS has lower NPC as well as LCOE than the grid-extension option. The computed break-even distances also confirmed that an HES is the more cost-effective option for the selected site, as the site requires at least $52 \mathrm{~km}$ of transmission lines, which exceeds the break-even grid-extension distances.

The results indicate that an HES is a more cost-effective way of supplying electricity to the remote rural villages that require more than $20.57 \mathrm{~km}$ of transmission line. If we assume the maximum cost for the grid-extension option, the break-even distance shortens to $9.69 \mathrm{~km}$, which means that an HES will be a cost-effective option for more areas in North Korea. Currently, North Korea's grid system is significantly degraded, so the transmission loss will be significant, in fact. Considering this aspect, the deployment of an HES is a more promising option for the remote rural region.

Moreover, many uncertainties and internal and external risks exist in North Korea at this moment. Thus, it would be reasonable to apply a discount rate that is even higher than $12 \%$ if this kind of rural electrification project is implemented in North Korea. Then, the break-even distance will become shorter than in our findings. This implies that an HES will be an even more cost-effective option in reality.

However, it should be noted that these results may not be consistent in other cases. The performance of an off-grid system is dependent on the natural resources of the site, which have a notable effect on the NPC. Thus, the optimal system configuration may differ by site. In addition, the result may be different by the target location's electricity demand. For instance, the off-grid system may have a limit; to cover the electricity demand of industrial complexes in a remote rural region, an on-grid system 
using conventional generation may be more cost-effective. In addition, there is a limitation in our study that the study was conducted under hypothetical conditions constructed based on a survey of North Korean defectors and the literature of other rural developing countries. If more detailed data regarding the energy consumption pattern of the village become available, our study can provide more concrete results. As an alternative, the study can be further developed by establishing different energy consumption scenarios of the region and observing the cost-effectiveness of the HES. Despite some of these limitations, our study is notable in that it is the first study to prove the cost-effectiveness of an HES in a rural village in North Korea through the quantitative analysis and results. Since there only exist the studies on the energy sector of North Korea, which are either qualitative analyses or macro-level of analyses, our site-specific analysis of an HES in the aspect of cost is unique and clearly distinguished from the existing studies. In addition, the cost-effectiveness of the HES confirmed in this study provides a significant implication in that the deployment of HESs can play a major role in accelerating the electrification rate of the rural areas in North Korea.

Author Contributions: Conceptualization, D.K. and T.Y.J.; methodology, D.K. and T.Y.J.; software, D.K.; validation, D.K. and T.Y.J.; formal analysis, D.K.; investigation, T.Y.J.; resources, D.K.; data curation, D.K.; writing-original draft preparation, D.K.; writing-review and editing, T.Y.J.; visualization, D.K.; supervision, T.Y.J.; project administration, T.Y.J.; funding acquisition, T.Y.J. All authors have read and agreed to the published version of the manuscript.

Funding: This research received no external funding.

Acknowledgments: The authors would like to thank Yong Gun Kim, Chief Research Fellow of Korea Environment Institute, for providing his insightful comments on our analysis. We also express our gratitude to anonymous reviewers and editor for their valuable feedbacks and suggestions which helped to improve the quality of paper.

Conflicts of Interest: The authors declare no conflict of interest.

\section{Appendix A. Cost and Technical Parameters for System Inputs in HOMER}

The values for costs and technical parameters are based on References [41-44]

Table A1. PV (Ningbo Ulca Solar PV module) [41].

\begin{tabular}{ccc}
\hline Parameters & Unit & Value \\
\hline Capital cost & $\$ / \mathrm{kW}$ & 1720 \\
Replacement cost & $\$ / \mathrm{kW}$ & 1720 \\
Operation and maintenance cost & $\$ /$ year & 8.68 \\
Lifetime & year & 25 \\
Derating factor & $\%$ & 80 \\
Ground reflectance & $\%$ & 20 \\
Temperature effects & $\% /{ }^{\circ} \mathrm{C}$ & -0.4 \\
Nominal operating cell temperature & ${ }^{\circ} \mathrm{C}$ & 47 \\
Efficiency at standard test conditions & $\%$ & 16.23 \\
\hline
\end{tabular}

Table A2. Wind turbine (Ahnhui Hummer Dynamo 100 kW) [42].

\begin{tabular}{ccc}
\hline Parameters & Unit & Value \\
\hline Capital cost & $\$ / \mathrm{kW}$ & $156,428.57$ \\
Replacement cost & $\$ / \mathrm{kW}$ & $156,428.57$ \\
Operation and maintenance cost & $\$ /$ year & 2647 \\
Lifetime & year & 20 \\
Rotor diameter & $\mathrm{M}$ & 21 \\
Blade length & $\mathrm{M}$ & 10 \\
Rated power & $\mathrm{m} / \mathrm{s}$ & 10.5 \\
Start-up wind speed & $\mathrm{m} / \mathrm{s}$ & 2 \\
Working wind speed & $\mathrm{m} / \mathrm{s}$ & $1.5-20$ \\
Survival wind speed & $\mathrm{m} / \mathrm{s}$ & 50 \\
\hline
\end{tabular}




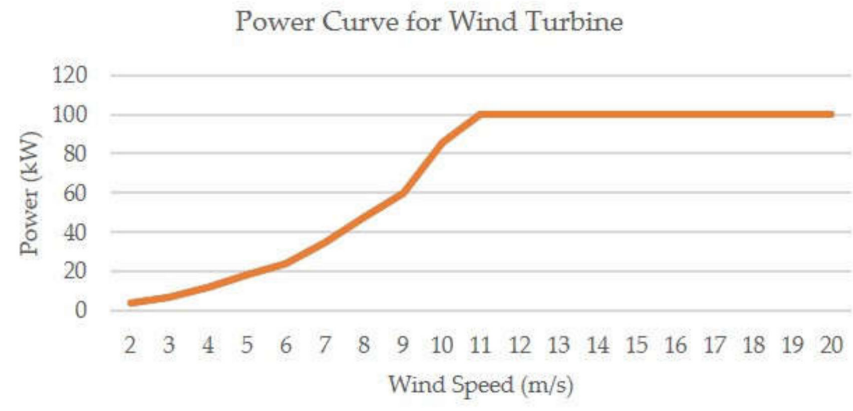

Figure A1. Power curve for wind turbine [42].

Table A3. Lead-acid battery (Surrette 4 KS 25P) [41].

\begin{tabular}{ccc}
\hline Parameters & Unit & Value \\
\hline Capital cost & $\$$ & 1259 \\
Replacement cost & $\$$ & 1100 \\
Operation and maintenance cost & $\$ /$ year & 0.02 \\
Lifetime & year & 12 \\
Throughput & $\mathrm{kWh}$ & 10,569 \\
String size & & 1 \\
Nominal voltage & $\mathrm{V}$ & 4 \\
Nominal capacity & $\mathrm{kWh}$ & 7.55 \\
Roundtrip efficiency & $\%$ & 80 \\
Initial state of charge & $\%$ & 100 \\
Minimum state of charge & $\%$ & 40 \\
\hline
\end{tabular}

Table A4. Energy storage system (ESS) (BMZ ESS 7.0) [43,44].

\begin{tabular}{ccc}
\hline Parameters & Unit & Value \\
\hline Capital cost & $\$$ & 4500 \\
Replacement cost & $\$$ & 4.500 \\
Operation and maintenance cost & \$/year & 90 \\
Lifetime & year & 20 \\
String size & & 1 \\
Nominal voltage & $\mathrm{V}$ & 55.5 \\
Nominal capacity & $\mathrm{kWh}$ & 6.74 \\
Maximum charge current & $\mathrm{A}$ & 80 \\
Minimum discharge current & $\mathrm{A}$ & 300 \\
Roundtrip efficiency & $\%$ & 95 \\
Initial state of charge & $\%$ & 100 \\
Minimum state of charge & $\%$ & 20 \\
\hline
\end{tabular}

Table A5. Diesel generator (Autosize genset) [41].

\begin{tabular}{ccc}
\hline Parameters & Unit & Value \\
\hline Capital cost & $\$ / \mathrm{kW}$ & 500 \\
Replacement cost & $\$ / \mathrm{kW}$ & 500 \\
Operation and maintenance cost & $\$ /$ op. hour & 0.003 \\
Lifetime & hour & 15,000 \\
Minimum load ratio & $\%$ & 0 \\
Minimum runtime & minute & 0 \\
Diesel fuel price & $\$ / \mathrm{L}$ & 1.04 \\
\hline
\end{tabular}


Table A6. Converter (generic) [41].

\begin{tabular}{ccc}
\hline Parameters & Unit & Value \\
\hline Capital cost & $\$ / \mathrm{kW}$ & 800 \\
Replacement cost & $\$ / \mathrm{kW}$ & 750 \\
Operation and maintenance cost & $\$ /$ year & 0 \\
Inverter lifetime & year & 15 \\
Inverter efficiency & $\%$ & 95 \\
Rectifier relative capacity & $\%$ & 100 \\
\hline
\end{tabular}

\section{References}

1. International Energy Agency. World Energy Outlook 2018; International Energy Agency: Paris, France, 2018 ; pp. 1-643. ISBN 978-92-64-30677-6.

2. Lal, S.; Raturi, A. Techno-Economic Analysis of a Hybrid Mini-Grid System for Fiji Islands. Int. J. Energy Environ. Eng. 2012, 3, 1-10. [CrossRef]

3. Kaldellis, J.K.; Gkikaki, A.; Kaldelli, E.; Kapsali, M. Investigating the Energy Autonomy of Very Small Non-Interconnected Islands. Energy Sustain. Dev. 2012, 16, 476-485. [CrossRef]

4. Jung, T.Y.; Kim, D.; Moon, J.; Lim, S. A Scenario Analysis of Solar Photovoltaic Grid Parity in the Maldives: The Case of Malahini Resort. Sustainability 2018, 10, 4045. [CrossRef]

5. Nerini, F.F.; Howells, M.; Bazilian, M.; Gomez, M.F. Rural Electrification Options in the Brazilian Amazon. Energy Sustain. Dev. 2014, 20, 36-48. [CrossRef]

6. Mondal, A.H.; Denich, M. Hybrid Systems for Decentralized Power Generation in Bangladesh. Energy Sustain. Dev. 2010, 14, 48-55. [CrossRef]

7. Shahzad, M.K.; Zahid, A.; Rashid, T.U.; Rehan, M.A.; Ali, M.; Ahmad, M. Techno-Economic Feasibility Analysis of a Solar-Biomass off Grid System for the Electrification of Remote Rural Areas in Pakistan Using HOMER Software. Renew. Energy 2017, 106, 264-273. [CrossRef]

8. Kim, H.; Jung, T.Y. Independent Solar Photovoltaic with Energy Storage Systems (ESS) for Rural Electrification in Myanmar. Renew. Sustain. Energy Rev. 2018, 82, 1187-1194. [CrossRef]

9. Ani, V.A.; Abubakar, B. Feasibility Analysis and Simulation of Integrated Renewable Energy System for Power Generation: A Hypothetical Study of Rural Health Clinic. J. Energy 2015, 2015, 1-7. [CrossRef]

10. Brenna, M.; Foiadelli, F.; Longo, M.; Abegaz, T.D. Integration and optimization of renewables and storages for rural electrification. Sustainability 2016, 8, 982. [CrossRef]

11. Yimen, N.; Hamandjoda, O.; Meva'a, L.; Ndzana, B.; Nganhou, J. Analyzing of a Photovoltaic/Wind/ Biogas/Pumped-Hydro Off-Grid Hybrid System for Rural Electrification in Sub-Saharan Africa-Case Study of Djoundé in Northern Cameroon. Energies 2018, 11, 2644. [CrossRef]

12. Kwak, D. KIET Monthly Industrial Economics; Korea Institute for Industrial Economics \& Trade: Sejong, Korea, 2018; pp. 18-27. (In Korean)

13. Bing, H.; Lee, S. The Current Status and Implication of the Renewable Energy in North Korea; Korea Institute for Industrial Economics \& Trade: Sejong, Korea, 2017; pp. 7-111. ISBN 979-11-88165-48-3. (In Korean)

14. Kim, I.; Kim, Y. Characteristics of Energy Usage and Emissions of Air Pollutants in North Korea. J. Korean Soc. Atmos. Environ. 2019, 35, 125-137. [CrossRef]

15. International Energy Agency. Energy Access Outlook 2017: From Poverty to Prosperity; International Energy Agency: Paris, France, 2017; pp. 1-140.

16. Energy Information Administration. International Analysis North Korea. Available online: https://www.eia. gov/beta/international/analysis.php?iso=PRK (accessed on 2 June 2019).

17. Statistics Korea. North Korea Statistics; In Korean. Available online: http://kosis.kr/bukhan/statisticsList/ statisticsList_01List.jsp (accessed on 27 February 2020).

18. Kim, K. Research Analysis on Energy Consumption in North Korea: Residential/Commercial/Public Sector; Korea Energy Economics Institute: Uiwang, Korea, 2013; pp. 1-152. ISBN 978-89-5504-444-7. (In Korean with English Abstract).

19. Korea Development Bank. The North Korea's Industry; Korea Development Bank: Seoul, Korea, 2015; pp. 1-1068. ISBN 979-11-956946-0-0. (In Korean) 
20. Kim, K. A Study on the Promotion of Cooperation Projects for DC and AC Conversion Facilities and Transmission and Distribution in Cheongin Area; Korea Energy Economics Institute: Uiwang, Korea, 2011; pp. 1-111. ISBN 978-89-5504-337-2. (In Korean with English Abstract).

21. Google Earth. North Korea. Available online: https://earth.google.com/web/@39.5497745,126.94757647, 379.41280857a,2204476.64743606d,35y,0h,0t,0r/data=ChIaEAoIL20vMDViN3EYAiABKAI (accessed on 7 September 2019).

22. Google Earth. Kibong-ri, Cholsan-gun, North Pyongan. Available online: https://earth.google.com/web/@39. $61525719,124.63235444,29.77839749 a, 1702.75179343 d, 35 y,-0 h, 0 t, 0 r$ (accessed on 7 September 2019).

23. Hrayshat, E.S. Techno-Economic Analysis of Autonomous Hybrid Photovoltaic-Diesel-Battery System. Energy Sustain. Dev. 2009, 13, 143-150. [CrossRef]

24. Kobayakawa, T.; Kandpal, T.C. A Techno-Economic Optimization of Decentralized Renewable Energy Systems: Trade-off between Financial Viability and Affordability-A Case Study of Rural India. Energy Sustain. Dev. 2014, 23, 92-98. [CrossRef]

25. Mamaghani, A.H.; Escandon, S.A.A.; Najafi, B.; Shirazi, A.; Rinaldi, F. Techno-Economic Feasibility of Photovoltaic, Wind, Diesel and Hybrid Electrification Systems for Off-Grid Rural Electrification in Colombia. Renew. Energy 2016, 97, 293-305. [CrossRef]

26. Central Bureau of Statistics Pyongyang. DPR Korea 2008 Population Census National Report; Central Bureau of Statistics Pyongyang: Pyongyang, Korea, 2009; pp. 1-273.

27. Bala, B.; Siddique, S.A. Optimal Design of a PV-Diesel Hybrid System for Electrification of an Isolated Island-Sandwip in Bangladesh Using Genetic Algorithm. Energy Sustain. Dev. 2009, 13, 137-142. [CrossRef]

28. Das, H.S.; Yatim, A.; Tan, C.W.; Lau, K.Y. Proposition of a PV/Tidal Powered Micro-Hydro and Diesel Hybrid System: A Southern Bangladesh Focus. Renew. Sustain. Energy Rev. 2016, 53, 1137-1148. [CrossRef]

29. Asian Development Bank. Developing Renewable Energy Mini-Grids in Myanmar: A Guidebook; Asian Development Bank: Manila, Philippines, 2017; pp. 1-58. ISBN 978-92-9261-060-9.

30. Bhagavathy, S.M.; Pilai, G. PV Microgrid Design for Rural Electrification. Designs 2018, 2, 33. [CrossRef]

31. Kang, D. An Analysis of Sustainable Energy System for North Korea: Cost Comparison of On-grid and Off-grid Systems in Rural Village of Haeju. Master's Thesis, Yonsei University, Seoul, Korea, December 2018.

32. The Institute for Peace Affairs. North Korean Human Geography. In Korean. Available online: http://www. cybernk.net/infoText/InfoAdminstList.aspx?mc=AD0102\&direct=1\&ac=A0322 (accessed on 22 June 2019).

33. NASA. NASA Prediction of Worldwide Energy Resources. Available online: https://power.larc.nasa.gov/ data-access-viewer/ (accessed on 3 April 2019).

34. Energy Information Agency. How Much Coal, Natural Gas, or Petroleum is Used to Generate a Kilowatthour of Electricity? Available online: https://www.eia.gov/tools/faqs/faq.php?id=667\&t=6 (accessed on 2 June 2019).

35. Dapice, D. Counting All of the Costs: Choosing the Right Mix of Electricity Sources in Vietnam to 2025. Harvard Kennedy School Ash Center for Democratic Governance and Innovation; Harvard Kennedy School Ash Center for Democratic Governance and Innovation: Cambridge, MA, USA, 2017; pp. 1-18.

36. Penn State College of Earth and Mineral Sciences. Basic Economics of Power Generation, Transmission and Distribution. Available online: https://www.e-education.psu.edu/eme801/node/530 (accessed on 20 July 2019).

37. Longe, O.M.; Ouahada, K.; Ferreira, H.C.; Chinnappen, S. Renewable Energy Sources Microgrid Design for Rural Area in South Africa. In Proceedings of the 2014 IEEE PES Innovative Smart Grid Technologies Conference, ISGT 2014, Washington, DC, USA, 19-22 February 2014. [CrossRef]

38. Kim, H.; Baek, S.; Choi, K.H.; Kim, D.; Lee, S.; Kim, D.; Chang, H.J. Comparative Analysis of On- and Off-Grid Electrification: The Case of Two South Korean Islands. Sustainability 2016, 8, 350. [CrossRef]

39. NRECA International, Ltd. Distribution Line Design and Cost Estimation for Rural Electrification Project. In Guides for Electric Cooperative Development and Rural Electrification; NRECA International, Ltd.: Arlington, VA, USA, 2010; pp. 161-192.

40. Earth Institute. Myanmar National Electrification Plan (NEP): Least-Cost Geospatial Electrification Planning Results; Earth Institute, Columbia University: New York, NY, USA, 2014; pp. 1-83.

41. Li, C.; Ge, X.; Zheng, Y.; Xu, C.; Ren, Y.; Song, C.; Yang, C. Techno-Economic Comparative Study of Grid-Connected PV Power Systems in Five Climate Zones, China. Energy 2018, 55, 263-272. [CrossRef] 
42. China Hummer. Products. Available online: http://www.chinahummer.cn/index.php/index/content/111 (accessed on 1 September 2019).

43. BMZ Energy Storage Systems. Data Sheet-ESS 7.0/9.0. Available online: https://d3g1qce46u5dao.cloudfront. net/data_sheet/170622_bmz_ess_70_datasheet_en_v032017.pdf (accessed on 18 March 2020).

44. Lazard. Lazard's Levelized Cost of Storage Analysis—Version 4.0; Lazard: New York, NY, USA, 2018; pp. 1-46.

(C) 2020 by the authors. Licensee MDPI, Basel, Switzerland. This article is an open access article distributed under the terms and conditions of the Creative Commons Attribution (CC BY) license (http://creativecommons.org/licenses/by/4.0/). 